ECCOMAS

\author{
Proceedia
}

UNCECOMP 2017

$2^{\text {nd }}$ ECCOMAS Thematic Conference on Uncertainty Quantification in Computational Sciences and Engineering M. Papadrakakis, V. Papadopoulos, G. Stefanou (eds.) Rhodes Island, Greece, 15-17 June 2017

\title{
FATIGUE DAMAGE MODEL OF WIND TURBINE COMPOSITE BLADES UNDER UNCERTAIN WIND SPEED
}

\author{
Chi Zhang ${ }^{1}$, and Huapeng Chen ${ }^{1^{*}}$ \\ ${ }^{1}$ Department of Engineering Science, University of Greenwich \\ Chatham Maritime, Kent, ME4 4TB, UK \\ \{c.zhang,h.chen\}@gre.ac.uk \\ *Corresponding author: h.chen@gre.ac.uk
}

Keywords: Composite Blade, S-N Curve, Goodman Diagram, Fatigue, Wind Speed, Blade Element Momentum.

\begin{abstract}
This paper presents a load spectrum and estimates the fatigue life of composite blades of horizontal axis wind turbines. The distributions of aerodynamic loads are analysed by beam element momentum theory, which affects the fatigue life of the blade along with other loads such as gravity and wind shear. The wind speed follows Weibull distribution and wind speed over an hour time is generated based on the offshore wind parameters. Then, the maximum stress caused by the deterministic dynamic loads, such as aerodynamic load, gravitational pressure and wind shear effect, is calculated using finite element model by Ansys. The stress cycle is established by Fast Fourier transform of the load spectrum which converts the time domain to frequency domain. Fatigue damage performance and the fatigue life estimate for blades are used to be predicted by fatigue damage rule for each cycle during the service life of offshore wind turbine based on the Goodman diagram and S-N curve. Finally, safe working life is predicted by applying the Miner's law for linear fatigue damage accumulation. A numerical example of composite blades of a wind turbine is investigated by proposed method to estimate fatigue life under uncertain wind speed in the offshore environment. From the results, the proposed method can provide an effective tool for evaluating the fatigue damage and assessing structural performance of the wind turbine blades under the uncertain offshore wind.
\end{abstract}




\section{INTRODUCTION}

With the increasing energy consumption in the world, renewable and clean energy such as wind resource have been considered as an alternative way to resolve the energy crisis. The wind turbine is one of offshore structure that captures the power of the wind and use it to generate clean energy. Since the rate of offshore wind turbines increases to multi-MW-size, one of the critical elements is the large composite blade due to the huge cost and fatigue damage. To adapt harsh marine environments and to resist fatigue load, glass-fibre reinforced composite materials are typically used to manufacture blades since these materials have better fatigue resistance and lighter weight than traditional materials, e.g., metals. One challenge in fatigue damage estimation is that the fatigue damage of reliable wind turbine blades is under complex load conditions, such as wind load, gravitational load, and wind shear effect $[1,2]$. Among these loads, the wind speed is significantly affected by the environmental condition with relatively high frequency and amplitude in offshore environments, which could be generated by deterministic distribution [3-5]. It is important to develop a method for analysing the blade fatigue damage before the blades fail catastrophically, which may destroy the entire wind turbine.

Most ongoing research on fatigue phenomena uses load spectra obtained by digital sampling or finite element (FE) model of wind turbine blades, which estimated the numerical solution at a location near the root of the blade [4]. Then, to obtain the cycles, traditional counting methods such as Rainflow Counting is used in $[3,6]$. However, computationally signal processing techniques (such as Fast Fourier transform) can also be used to calculate the fatigue cycles according to the frequency of the load spectra [7]. Based on Goodman diagram and S-N curve, the equivalent load spectra for each cycle can be investigated $[7,8,9]$. This stress is utilised to estimate fatigue damage in the blade using Miner's rule [5,6], and then fatigue life is estimated.

This study presents a method for investigating the fatigue damage of a composite wind turbine blade. The Fast Fourier transform is used here to obtain the load cycles, based on the data of stress spectrum by FE model solution. The Miner's law is used to predict the fatigue damage during the designed service life of offshore wind turbine by the S-N curve and Goodman diagram. A numerical example of composite blades of a wind turbine is investigated to estimate fatigue damage under uncertain wind speed, following Weibull distribution describing the wind in the offshore environment. Results show that FE model can take the variable wind speed with other blade loads into account and the frequency of stress can be obtained. Then, the stress in each cycle can be converted into fatigue stress. The proposed method can be further used for determining the resistance of the composite blades based on $\mathrm{S}-\mathrm{N}$ curves. The fatigue damage of composite blades can be predicted by Miner's law based on combining fatigue stress and life cycles in each cycle. The fatigue life can be calculated before the cumulative damage exceeds unity. From the results, the proposed method can both provide a useful tool for evaluating the fatigue damage and assess structural performance of the wind turbine blades under the uncertain offshore wind.

\section{ANALYSIS OF BLADE LOADS}

Loads of the wind turbine blades contain both deterministic and stochastic load under different wind speed, such as aerodynamic load, wind shear, gravity load and periodic load $[1,2]$. However, the loads can be imported into the finite element model in fatigue analysis to investigate the maximum stress in the blade.

\subsection{Aerodynamic loads}

Blade element momentum (BEM) method is the core theory to analyse wind turbine aerodynamics on the blades. This BEM theory treats the revolving rotor as an actuator disc that 
combines both blade element theory and one-dimensional momentum theory in both the rotor axial and tangential direction [2]. Both rotor axial and tangential induction factors that describe the airflow speed change are introduced in the one-dimensional momentum method to calculate the wind thrust and rotor motivation torque. The blade element theory separates the blade into several elements and ignores the mutual influence between two adjacent elements. The aerodynamic loads on each element are dependent on its local airfoil characteristics, i.e. its lift and drag coefficients. The sum of these loads yields the total loads on the blade in X and Y directions [1], respectively, namely

$$
\begin{aligned}
& F_{Y p}=\int d F_{Y p}=\frac{1}{2} \frac{B}{2 \pi} \rho \int_{0}^{2 \pi} \int_{0}^{R}\left(C_{L} \cos \alpha+C_{D} \sin \alpha\right) c \omega^{2} d \theta d r \\
& F_{X p}=\int d F_{X p}=\frac{1}{2} \frac{B}{2 \pi} \rho \int_{0}^{2 \pi} \int_{0}^{R}\left(C_{L} \sin \alpha-C_{D} \cos \alpha\right) c \omega^{2} d \theta d r
\end{aligned}
$$

where $B$ is the number of blades; $\rho$ is the air density; $c$ is the length of chord; $\omega$ is the angular velocity of the rotor; $r$ is the radius of the section; $\theta$ is the azimuth angle of the rotor; $C_{L}$ is the airfoil lift coefficient; $C_{D}$ is the drag coefficient; and $\alpha$ is inflow angle.

Therefore, the flapwise moment and edgewise at the root of the blade are

$$
M_{X p}=\int_{0}^{R} r d F_{Y p}, \quad M_{Y p}=-\int_{0}^{R} r d F_{X p}
$$

where $p$ represents the pressure centre of the airfoil.

\subsection{Wind shear}

The wind shear effect depends on the height of the wind turbine, and the description of this relationship is exponential. Since the wind turbine becomes MW recently, the radius of the blade increases significantly. The wind speed will significantly change in different positions of the blade, so the wind shear effect should be considered. According to [10], the wind speed at the height of the sea level can express as

$$
V(y)=V_{h}\left(1+\frac{r \cos \theta}{h}\right)^{m}
$$

where $h$ is the height of the hub of the wind turbine, $V_{h}$ is wind speed at the hub, $m$ is wind shear exponent, normally between 0.1 and 0.25 .

\subsection{Gravity}

For large wind turbine blades, the blade is subjected to gravity during service time, which is periodic changing by azimuth angle $\theta$ of the rotor. The gravity per element of the blade on each axis can be obtained as

$$
F g=\left[\begin{array}{ccc}
\cos \theta & 0 & -\sin \theta \\
0 & 1 & 0 \\
\sin \theta & 0 & \cos \theta
\end{array}\right]\left\{\begin{array}{c}
0 \\
0 \\
M g
\end{array}\right\}
$$

where $F_{g}$ is the gravity loads, $M$ is the mass of the blade, and $g$ is the gravity acceleration. The gravity load is considered as an axial load, which does not vary with time.

\subsection{Distribution of wind speed}

According to [3], the Weibull frequency distribution is adopted to describe the wind speed. Therefore, the probabilistic density function $f(v)$ and cumulative distribution function $F(v)$ are

$$
f(v)=\frac{K}{C}\left(\frac{V}{C}\right)^{K-1} e^{-\left(\frac{V}{C}\right)^{K}}
$$




$$
F(v)=1-e^{-\left(\frac{V}{C}\right)^{K}}
$$

where $K$ is the shape parameter and $C$ is the scale parameter of the distribution.

\section{FATIGUE ANALYSIS}

Fatigue analysis has been considered as a critical part of the design process of wind turbine blades. According to the results of different wind speed, the loads in wind turbine blades are established. Fatigue life was estimated by using the Fast Fourier transform for the cycle, Goodman diagrams and the load spectrum to get the fatigue stress and the $\mathrm{S}-\mathrm{N}$ linear damage equation for accumulating the damage [5,9]. By combining these methods, a dynamic structural problem for the fatigue can be converted into a static structural problem.

\subsection{Finite element blade model}

In this study, the finite element model is introduced in Ansys software for fatigue analysis under various wind speeds to get the maximum stress. A composite blade considered in this study is the same geometry to the $1.5 \mathrm{MW}$ Sandia reference wind turbine composite blade [4].

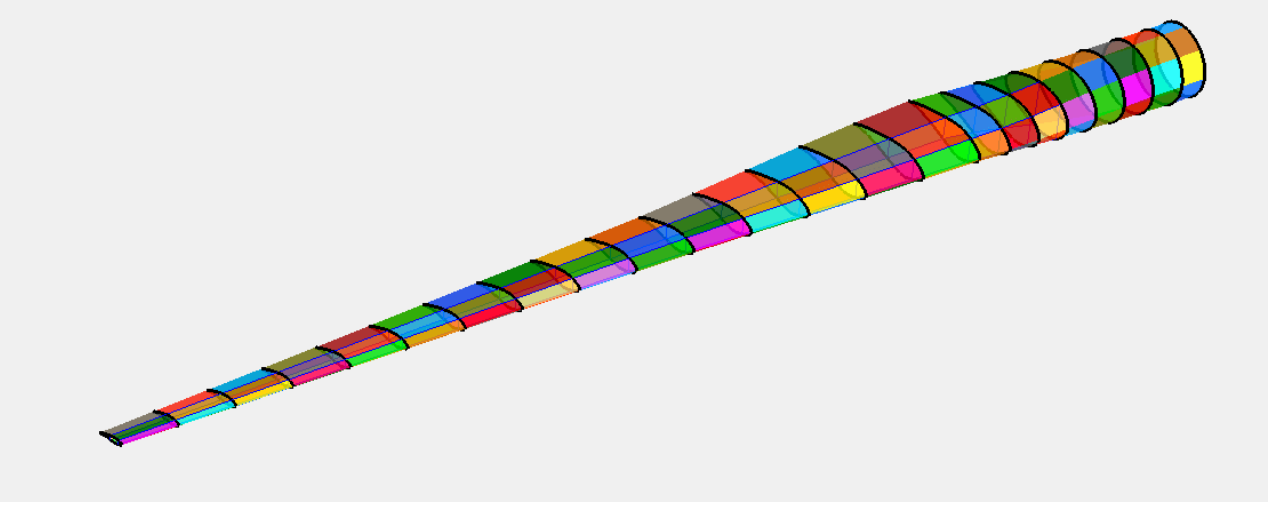

Figure 1: Structural design of 1.5MW wind turbine blade by NuMAD based on the Sandia database [4]

The aerodynamic properties, e.g., airfoil type, chord length, and twist angle, are the same as those from the design data. A refined blade geometry model (Figure 1) was generated in NuMAD by connecting 24 airfoils, which smooth the transition from section to section and reduce the stress concentration.

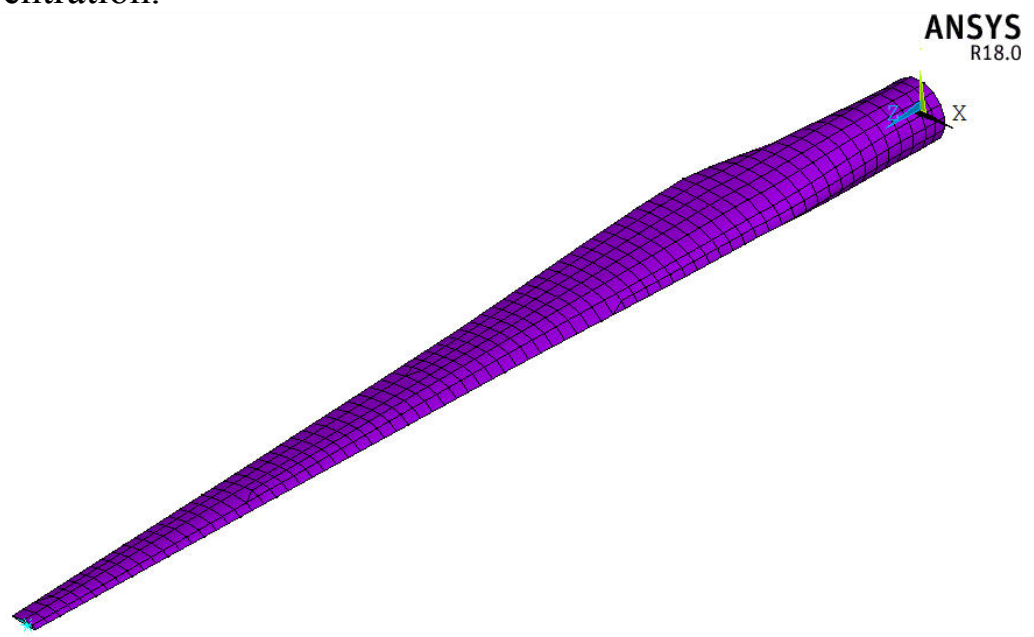

Figure 2: The meshed and geometrical model of wind turbine blades based on 1.5MW Sandia using Ansys 18.0 
The NuMAD can export the 3D structural design into Ansys file. The meshed model (Figure 2) generated by Ansys 18.0, which implements layered shell 281 elements for the structure. By applying the blades loads into the model, the solution of maximum stress can be analysed in FE model. In this study, the maximum stress is assumed as the fatigue stress in these loads to calculate the fatigue damage in this certain wind speed.

\subsection{Fast Fourier transform}

According to the previous section, it generates random wind speed numbers by the Weibull distribution with scale parameter $C$ and shape parameter $K$ during the given period. The Fast Fourier transform (FFT) is used here to obtain the fatigue cycles, which will be used to analyse the uncertain stress during the particular time. A dynamic structural problem for the fatigue can be converted into a static structural problem [7].

Fourier transform converts the time domain to frequency domain by integrating over the axis of whole time. The Fast Fourier transform technique is used to derive the wind frequency by converting the time-domain component of wind stress into frequency from a spectrum using the transfer equation

$$
X(u)=\int_{-\infty}^{\infty} f(x) e^{-2 \pi i u x} d x
$$

where $X(u)$ is the frequency domain function, $u$ is the spatial frequency, and $f(x)$ is the spatial domain function.

By the FFT method, the frequency for the uncertain wind speed during the measuring time is established. The fatigue cycles by wind speed can be therefore used to analyse the damage for the wind turbine blades.

\subsection{Goodman diagram}

Constant life diagrams are graphical representations of the safe regime of constant amplitude loading for a given specified life, e.g. the endurance limit or infinite life [6]. These diagrams can be drawn in some ways, depending on which parameters are selected to describe the constant amplitude cyclic loading, such as Goodman diagram [9].

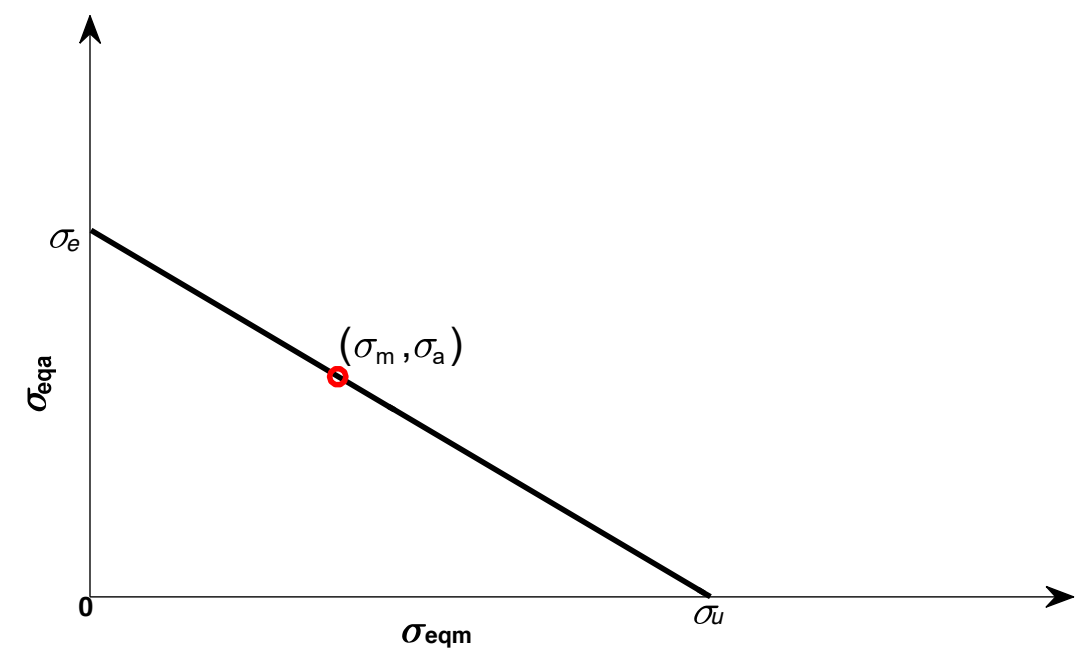

Figure 3: An example of Goodman diagram showing amplitude stress $\sigma_{\text {eqa }}$ Vs. mean stress $\sigma_{\text {eqm }}$

Constant amplitude cyclic loading can be defined by specifying the following parameters, i.e. maximum stress and minimum stress. The Goodman diagram can give the equivalent stress 
under different mean stress. A simple Goodman diagram without considering the stress ratio can be expressed as

$$
\sigma_{e q a}=\frac{\sigma_{a}}{\sigma_{m}-\sigma_{u}}\left(\sigma_{e q m}-\sigma_{u}\right)
$$

where $\sigma_{\text {eqa }}$ is the equivalent stress in this cycle when the equivalent mean stress $\sigma_{\text {eqm }}$ is given, $\sigma_{a}$ is the amplitude stress, and $\sigma_{m}$ is the mean stress in this cycle, $\sigma_{u}$ is the ultimate stress for the material.

Figure 3 gives an illustrative Goodman diagram used in this study. The fatigue stress should use the equal amplitude stress when the average stress is null $\left(\sigma_{m}=0\right)$ by Goodman diagram for the wind turbine blade, and this amplitude stress is expressed as $\sigma_{e}$.

\subsection{S-N curve}

To calculate the damage of composite blades by S-N curve, it is necessary to know the fatigue life cycles under constant equal amplitude loading obtained by Goodman diagram. Fatigue properties of materials are usually expressed in the form of S-N curves according to the experimental data, i.e. stress amplitude versus the number of cycles to failure.

According to $[6,8,9]$ a typical following $\mathrm{S}-\mathrm{N}$ curve model can be equalled as

$$
\sigma_{e}=A-B \lg N, \text { or } \quad r=\frac{\sigma_{e}}{\sigma_{u}}=a-b \lg N
$$

where $r=\sigma_{e} / \sigma_{u}$ is the stress ratio, $A$ and $B$ are parameters depending on the material, which also can be expressed as $a \sigma_{u}$ and $b \sigma_{u}$. Figure 4 represents the relationship between the stress ratio and the stress cycles to calculate the fatigue damage.

The fatigue life cycles $N$ can be obtained in this graph given an amplitude stress $\sigma_{e}$. The damage in this cycle is $1 / N$ by assuming the total damage is unity.

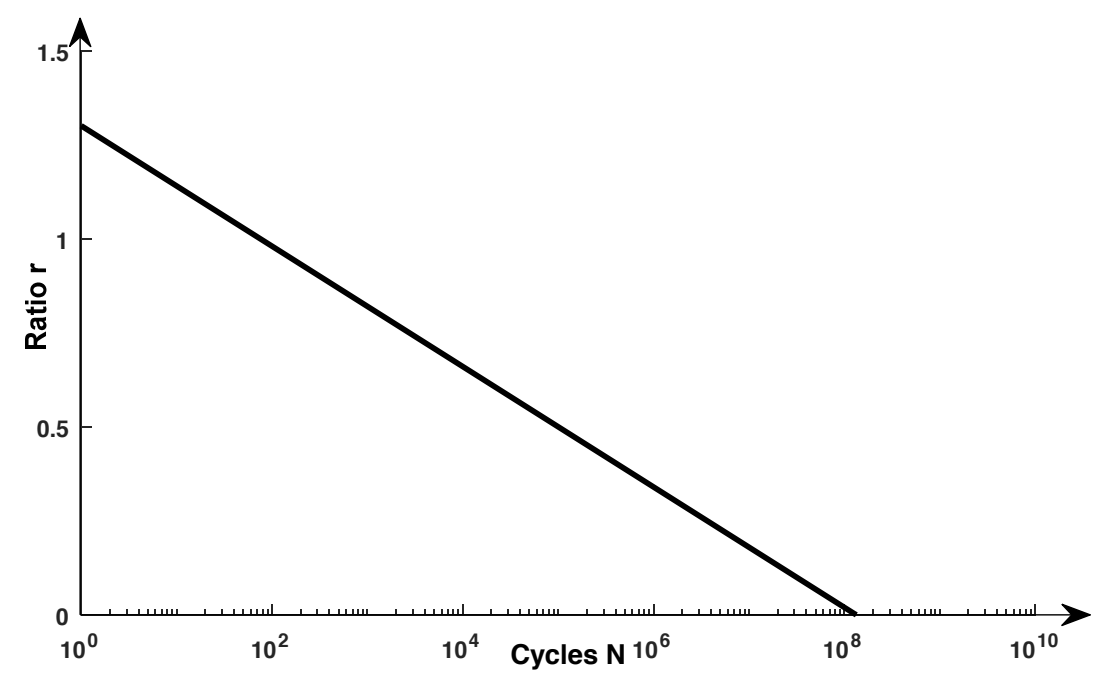

Figure 4: An example of the S-N curve showing linear relationship between the fatigue cycles $\mathrm{N}$ and constant ratio $\mathrm{r}$

\subsection{Miner law}

The fatigue damage due to each stress component can be accumulated by Miner's rule. According to Miner's rule, the structure is defined as failure when the cumulative damage $D$ exceeds unity $[1,5,9]$, where $D$ is defined as

$$
D=\sum_{i} \frac{n_{i}}{N_{i}}
$$


where $n_{i}$ is the load cycle number for a stress range $i$, and $N_{i}$ is the allowable load cycle number associated with $i$.

By the method mentioned above, the damage per hour can be generated and the total hour of fatigue life can be estimated. To achieve the design code of wind turbine concerning the total service life, some maintenance strategies may increase the performance of the wind turbine blade and prevent the structural failure.

\section{NUMERICAL EXAMPLE}

Based on the method described in the previous section, a numerical example can be performed to demonstrate the effectiveness of the proposed method. In this study, fatigue damage in composite blades of the wind turbine under offshore wind condition is analysed, and then the fatigue life can be evaluated.

The measurement of deterioration in this paper is therefore based on the Miner's law. When the cumulative fatigue damage exceeds unity, the composite blade is considered as it loses its mechanical properties and could not service anymore. Before this situation happens, the blade structure can be treated as nearly failed and a proper maintenance strategy will be taken.

In the following example, the $1.5 \mathrm{MW}$ Sandia reference wind turbine composite blade [4] is analysed according to the method discussed above. The aerodynamic properties, e.g., airfoil type, chord length, and twist angle, are the same as the design data. The Weibull distribution of the wind speed of European offshore wind farm for the whole year is estimated, where the shape parameter $K=2.0$ and the scale parameter $C=15 \mathrm{~m} / \mathrm{s}$. Therefore, the wind field simulation per minute for 1 hour can be randomised in MATLAB, as shown in Figure 5.
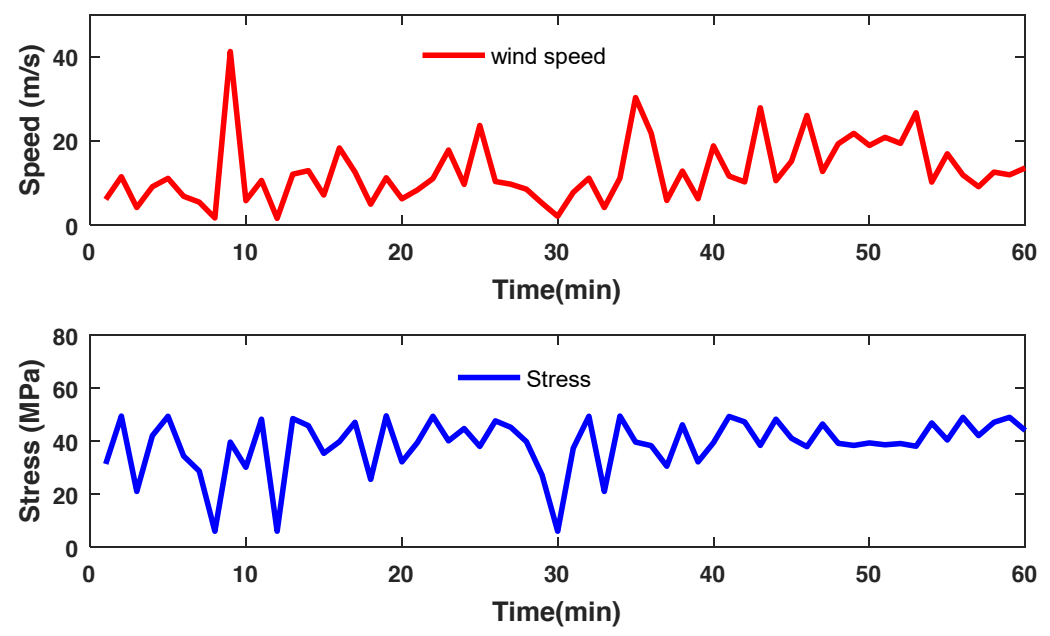

Figure 5: Prediction of wind speed generated by Weibull distribution and results of maximum stress to time spectrum during one hour

From the results, the aerodynamic loading can be separated into lift loading and drag loading along with each blade element by BEM method. The offshore wind turbine is typically located just above the sea level thus the wind shear effect could not be ignored. The height of the wind turbine hub is assumed 50 meters, and wind shear exponent is taken 0.1 in this study. The gravity in this study considered as an axial load in the gravity centre of the blade.

The solution of the FE model generated by NuMAD in Ansys involves the blade loads including aerodynamic load, wind shear, and gravity load. The maximum stress in certain wind speed can be regarded as equivalent stress in load analysis for this $1.5 \mathrm{MW}$ blade. The stress to time diagram for 1-hour given by wind field simulation is established in Figure 5. The spectra 
of maximum stress versus wind speeds are shown in Figure 6 according to the existing data from [1] by wind turbine blade of FE model.

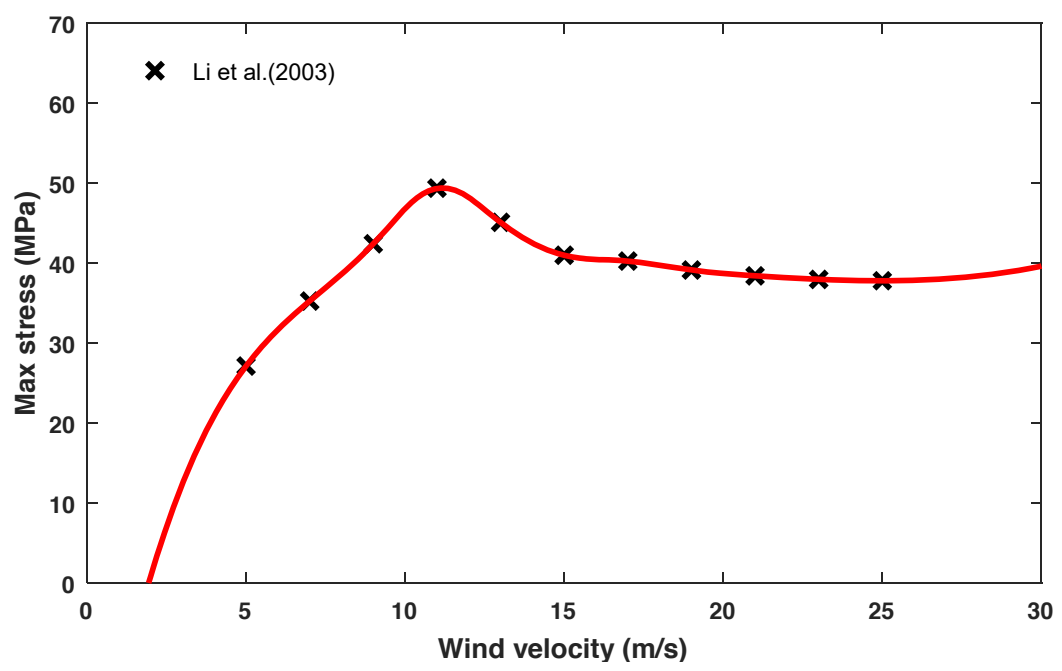

Figure 6: The maximum stress in various wind speed

The maximum stress in wind turbine blade depends on the wind speed shown in Figure 6. As the wind speed increases, the stress also increase. However, after reaching a certain wind speed, the maximum stress reduces and then becomes stable. When the wind speed exceeds the design wind speed for the wind turbine, the attack angle decreases, leading to the reducing wind surface. The wind turbine keeps the stable angular velocity to produce the stable power when the turbulence of wind speed is high.

To get the cycle of the fatigue stress in this measuring time, the FFT is used to obtain the frequency during one hour. The cycles can be used to analyse the fatigue damage for the wind turbine blades. Figure 7 shows the result of the frequency of the stress during the time. The first five peak points in amplitude are used to establish the stress cycle during the time.
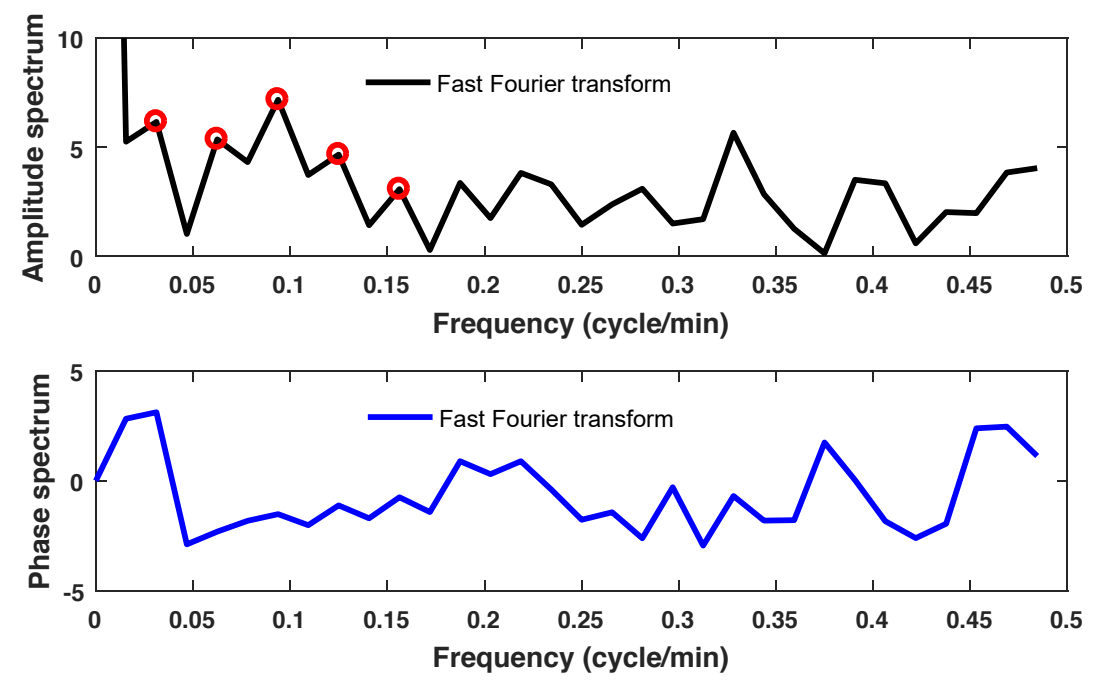

Figure 7: The frequency of amplitude and phase by FFT

The number of the cycles can be obtained by the frequency and the whole period. Each cycle has the maximum stress $\sigma_{\max }$ and minimum stress $\sigma_{\min }$, and therefore the mean stress $\sigma_{m}$ and amplitude $\sigma_{a}$ for this cycle can be calculated. For the glass-fibre material, assuming the ultimate 
stress $\sigma_{u}$ in Goodman diagram $\sigma_{u}=100 \mathrm{MPa}$, the equivalent stress $\sigma_{e}$ at $\sigma_{e q m}=0$ can be obtained. According to S-N curve, the life cycles $N_{i}$ at $\sigma_{e}$ can be calculated. The $a$ and $b$ for one type of glass fibre material is 1.3 and 0.16 , respectively. The Miner's law accumulates damage by the life cycles, and the failure will occur when the damage accumulates to a certain critical value of unity.

Table 1 shows results of the maximum stress $\sigma_{\max }$, minimum stress $\sigma_{\min }$, the mean stress $\sigma_{m}$ and amplitude $\sigma_{a}$ for every cycle in each peak point. The equivalent stress $\sigma_{e}$ is obtained by Goodman diagram for glass fibre material. The life cycles $N$ in every cycle is predicted by the proposed S-N curve in this table since the equivalent stress $\sigma_{e}$ has been obtained in each cycle. Then the fatigue damage $D$ is reciprocal of life cycle $N$ obtained by $\mathrm{S}-\mathrm{N}$ curve in this cycle. From this table, the total damage is $7.55 \mathrm{E}-06$ by summing all the damage in each cycle in this 1 hour.

\begin{tabular}{ccccccccc}
\hline & $\sigma_{\max }(\mathrm{MPa})$ & $\sigma_{\min }(\mathrm{MPa})$ & $\sigma_{m}(\mathrm{MPa})$ & $\sigma_{a}(\mathrm{MPa})$ & $\sigma_{e}(\mathrm{MPa})$ & $N($ cycles $)$ & $D$ \\
\hline Peak & 1 & 49.40 & 5.87 & 27.63 & 21.77 & 30.08 & $1.76 \mathrm{E}+06$ & $5.68 \mathrm{E}-07$ \\
cycle & 2 & 49.35 & 20.94 & 35.14 & 14.21 & 21.90 & $5.70 \mathrm{E}+06$ & $1.75 \mathrm{E}-07$ \\
\hline Peak & 2 & 49.36 & 5.87 & 27.61 & 21.75 & 30.04 & $1.77 \mathrm{E}+06$ & $5.66 \mathrm{E}-07$ \\
cycle & 4 & 49.40 & 5.87 & 27.63 & 21.77 & 30.08 & $1.76 \mathrm{E}+06$ & $5.68 \mathrm{E}-07$ \\
& & 49.35 & 20.94 & 35.14 & 14.21 & 21.90 & $5.70 \mathrm{E}+06$ & $1.75 \mathrm{E}-07$ \\
& 48.84 & 37.83 & 43.34 & 5.51 & 9.72 & $3.29 \mathrm{E}+07$ & $3.04 \mathrm{E}-08$ \\
\hline Peak & 3 & 49.36 & 5.87 & 27.61 & 21.75 & 30.04 & $1.77 \mathrm{E}+06$ & $5.66 \mathrm{E}-07$ \\
cycle & 6 & 49.40 & 5.87 & 27.63 & 21.77 & 30.08 & $1.76 \mathrm{E}+06$ & $5.68 \mathrm{E}-07$ \\
& & 49.26 & 5.87 & 27.56 & 21.70 & 29.95 & $1.79 \mathrm{E}+06$ & $5.58 \mathrm{E}-07$ \\
& 49.35 & 20.94 & 35.14 & 14.21 & 21.90 & $5.70 \mathrm{E}+06$ & $1.75 \mathrm{E}-07$ \\
& 49.17 & 37.83 & 43.50 & 5.67 & 10.03 & $3.15 \mathrm{E}+07$ & $3.18 \mathrm{E}-08$ \\
& 48.84 & 37.92 & 43.38 & 5.46 & 9.65 & $3.33 \mathrm{E}+07$ & $3.01 \mathrm{E}-08$ \\
\hline Peak & 4 & 49.36 & 5.87 & 27.61 & 21.75 & 30.04 & $1.77 \mathrm{E}+06$ & $5.66 \mathrm{E}-07$ \\
cycle & 8 & 48.41 & 5.87 & 27.14 & 21.27 & 29.20 & $2.00 \mathrm{E}+06$ & $5.01 \mathrm{E}-07$ \\
& 49.40 & 25.47 & 37.43 & 11.96 & 19.12 & $8.51 \mathrm{E}+06$ & $1.18 \mathrm{E}-07$ \\
& 49.26 & 5.87 & 27.56 & 21.70 & 29.95 & $1.79 \mathrm{E}+06$ & $5.58 \mathrm{E}-07$ \\
& 49.35 & 20.94 & 35.14 & 14.21 & 21.90 & $5.70 \mathrm{E}+06$ & $1.75 \mathrm{E}-07$ \\
& 49.17 & 37.83 & 43.50 & 5.67 & 10.03 & $3.15 \mathrm{E}+07$ & $3.18 \mathrm{E}-08$ \\
& 48.84 & 37.92 & 43.38 & 5.46 & 9.65 & $3.33 \mathrm{E}+07$ & $3.01 \mathrm{E}-08$ \\
& 48.84 & 41.99 & 45.42 & 3.43 & 6.28 & $5.40 \mathrm{E}+07$ & $1.85 \mathrm{E}-08$ \\
\hline Peak & 5 & 49.36 & 20.94 & 35.15 & 14.21 & 21.91 & $5.69 \mathrm{E}+06$ & $1.76 \mathrm{E}-07$ \\
cycle & 9 & 48.41 & 5.87 & 27.14 & 21.27 & 29.20 & $2.00 \mathrm{E}+06$ & $5.01 \mathrm{E}-07$ \\
& 49.40 & 25.47 & 37.43 & 11.96 & 19.12 & $8.51 \mathrm{E}+06$ & $1.18 \mathrm{E}-07$ \\
& 49.26 & 37.88 & 43.57 & 5.69 & 10.08 & $3.13 \mathrm{E}+07$ & $3.20 \mathrm{E}-08$ \\
& 49.35 & 5.87 & 27.61 & 21.74 & 30.03 & $1.77 \mathrm{E}+06$ & $5.65 \mathrm{E}-07$ \\
& 49.17 & 30.43 & 39.80 & 9.37 & 15.57 & $1.42 \mathrm{E}+07$ & $7.04 \mathrm{E}-08$ \\
& 48.18 & 37.83 & 43.01 & 5.18 & 9.08 & $3.61 \mathrm{E}+07$ & $2.77 \mathrm{E}-08$ \\
& 48.84 & 37.92 & 43.38 & 5.46 & 9.65 & $3.33 \mathrm{E}+07$ & $3.01 \mathrm{E}-08$ \\
& 48.84 & 41.99 & 45.42 & 3.43 & 6.28 & $5.40 \mathrm{E}+07$ & $1.85 \mathrm{E}-08$ \\
\hline & & & & & & $\sum D$ & $7.55 \mathrm{E}-06$ \\
\hline
\end{tabular}

Table 1: The fatigue loads and damage in each cycle during 1-hour measuring period

The estimated fatigue life of this glass fibre reinforced composite blade is 


$$
Y=\frac{1}{\sum D \times 24 \times 365}=15.1 \text { year }
$$

Since the design code expects the service time of offshore wind turbine blades is 25 years, some proper maintenance strategies should be taken during the design process.

\section{CONCLUSIONS}

In this study, the fatigue life was estimated by linear Miner's law based on the well-known S-N linear damage equation, the equivalent load spectrum by Goodman diagram with analysing the blade loads in FE model of the wind turbine blade. The calculation of the load spectrum and the fatigue performance of wind turbine blade is discussed by analysing the blade loads in FE model using the deterministic method.

From the sample spectrum data during short period operation, the data were rearranged load cycles, maximum stress, minimum stress, mean stress, the amplitude of the stress, and equivalent stress by FFT and Goodman diagram, and then reordered as life cycle and damage for each cycle by S-N curve. Based on the Miner's law, the accumulation of fatigue damage can be obtained during the sample measuring time. The total service time of the wind turbine blade is estimated as 15.1 years without maintenance. Further work is needed to determine the optimum repair strategy for the composite blades of an offshore wind turbine according to the obtained results.

\section{REFERENCES}

[1] D.Y. Li, Z.Q. Ye, Y. Chen, N.S. Bao, Load spectrum and fatigue life analysis of the blade of horizontal axis wind turbine. Wind Engineering, 27, 495-506, 2003.

[2] L. Wang, X. Liu, N. Renevier, M. Stables, G.M. Hall, Nonlinear aeroelastic modelling for wind turbine blades based on blade element momentum theory and geometrically exact beam theory. Energy, 76, 487-501, 2014.

[3] J.A. Epaarachchi, P.D. Clausen, The development of a fatigue loading spectrum for small wind turbine blades. Journal of wind engineering and industrial aerodynamics, 94, $207-$ 223, 2006.

[4] Y. Bazilevs, M.-C. Hsu, I. Akkerman, S. Wright, K. Takizawa, B. Henicke, T. Spielman, T. E. Tezduyar, 3D simulation of wind turbine rotors at full scale. Part I: Geometry modeling and aerodynamics. International Journal for Numerical Methods in Fluids, $\mathbf{6 5}$, 207-235, 2011.

[5] M.M. Shokrieh, R. Rafiee, Simulation of fatigue failure in a full composite wind turbine blade. Composite Structures, 74, 332-342, 2006.

[6] M. Grujicic, G. Arakere, E. Subramanian, V. Sellappan, A. Vallejo, M. Ozen, Structuralresponse analysis, fatigue-life prediction, and material selection for $1 \mathrm{MW}$ horizontalaxis wind-turbine blades. Journal of materials engineering and performance, 19, 790$801,2010$.

[7] J.M. Ha, H. Oh, J. Park, B.D. Youn, Classification of operating conditions of wind turbines for a class-wise condition monitoring strategy. Renewable Energy, 103, 594-605, 2017. 
[8] J.F. Mandell, D.D. Samborsky, L. Wang, N.K. Wahl, New fatigue data for wind turbine blade materials. Journal of solar energy engineering, 125, 506-514, 2003.

[9] J.C. Marin, A. Barroso, F. Paris, J. Canas, Study of fatigue damage in wind turbine blades. Engineering failure analysis, 16, 656-668, 2009.

[10] M.C. Holtslag, W. Bierbooms, G.J.W. Bussel. Wind turbine fatigue loads as a function of atmospheric conditions offshore. Wind Energy, 10, 1917-1932, 2016. 